\title{
STUDIES OF ENERGETIC CONFINED ALPHAS USING THE PELLET CHARGE EXCHANGE DIAGNOSTIC ON TFTR
}

\section{BY}

M.P. PETROV, R.V. BUDNY, H.H. DUONG, ET AL.

\author{
JULY 1995
}
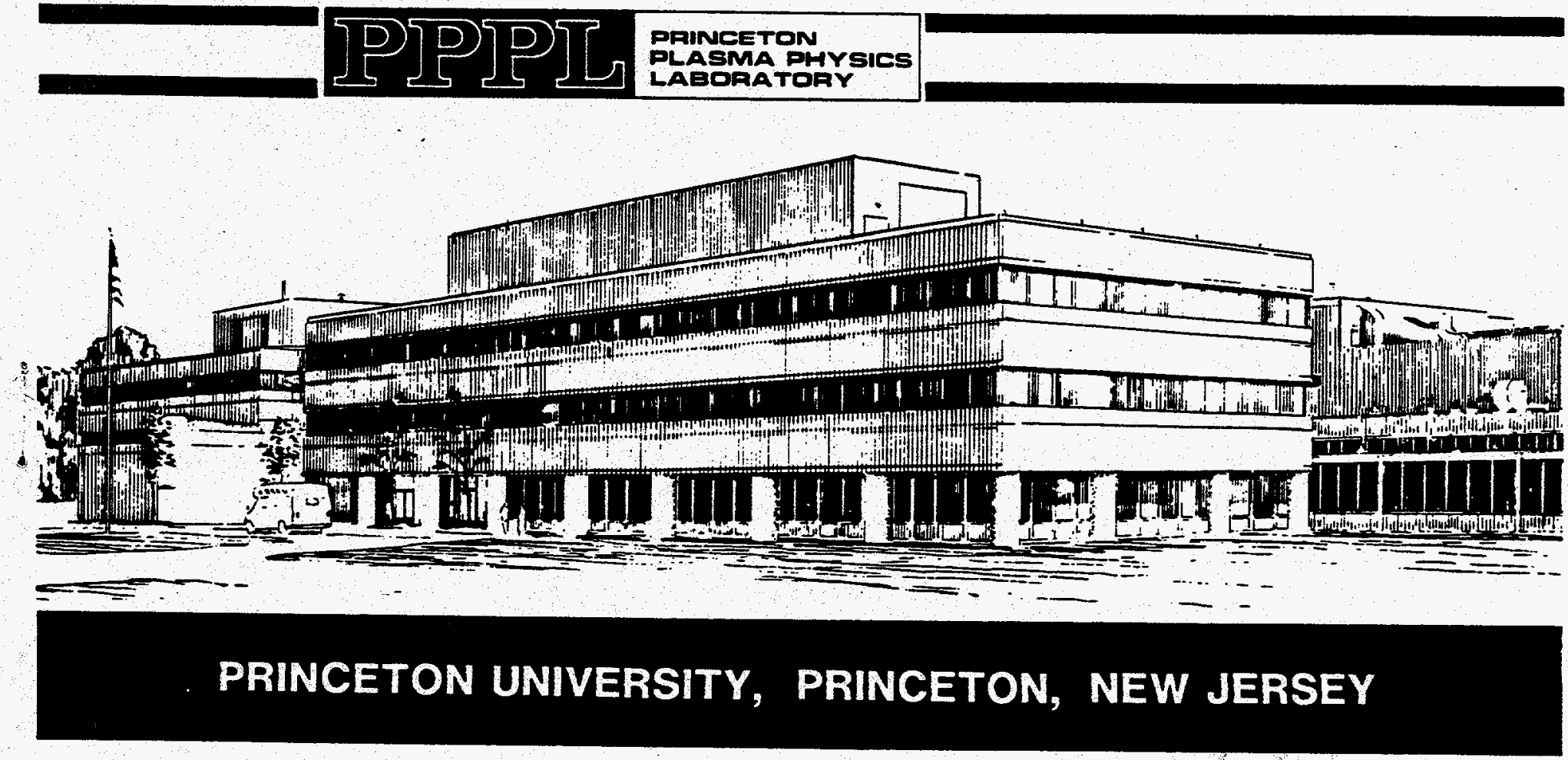


\section{NOTICE}

This report was prepared as an account of work sponsored by an agency of the United States Government. Neither the United States Government nor any agency thereof, nor any of their employees, makes any warranty, express or implied, or assumes any legal liability or responsibility for the accuracy, completeness, or usefulness of any information, apparatus, product, or process disclosed, or represents that its use would not infringe privately owned rights. Reference herein to any specific commercial produce, process, or service by trade name, trademark, manufacturer, or otherwise, does not necessarily constitute or imply its endorsement, recommendation, or favoring by the United States Government or any agency thereof. The views and opinions of authors expressed herein do not necessarily state or reflect those of the United States Government or any agency thereof.

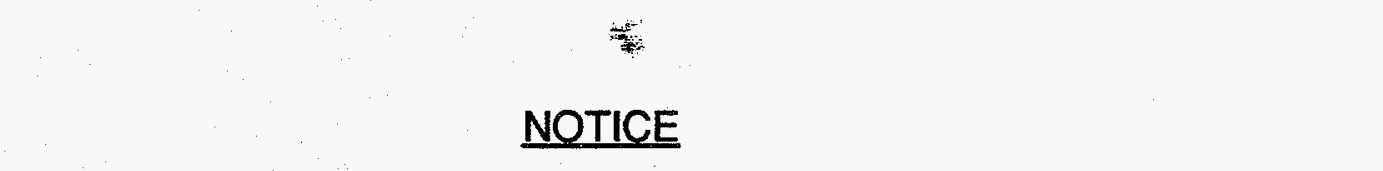

This report has been reproduced from the best available copy.

Available in paper copy and microfiche.

Number of pages in this report: 22

DOE and DOE contractors can obtain copies of this report from:

Office of Scientific and Technical Information

P.O. Box 62

Oak Ridge, TN 37831 ;

(615) 576-8401.

This report is publicly available from the:

National Technical Information Service

Department of Commerce

5285 Port Royal Road

Springfield, Virginia 22161

(703) $487-4650$ 


\section{DISCLAIMER}

Portions of this document may be illegible in electronic image products. Images are produced from the best available original document. 


\title{
Studies of Energetic Confined Alphas Using the Pellet Charge Exchange Diagnostic on TFTR
}

\author{
M. P. Petrov ${ }^{+}$, R. V. Budny ${ }^{\star}$, H. H. Duong ${ }^{\dagger}$, R. K. Fisherx, N. N. Gorelenkov", \\ J. M. McChesneyx, D. K. Mansfield ${ }^{*}$, S. S. Medley , P. B. Parks, M. H. Redi", \\ A. L. Roquemore* \\ *Princeton Plasma Physics Laboratory P.O.Box 451, Princeton, New Jersey 08543 USA \\ $x$ General Atomics, San Diego, California 92186 USA \\ t General Atomics ORAU Fellow \\ $+A$. F. loffe Physical-Technical Institute, St. Petersburg, 194021 Russia \\ \# TRINITI, Troitsk, 142092 Russia
}

\begin{abstract}
Results from recent DT experiments on TFTR to measure the energy distribution and radial density profile of fast confined alphas with the use of Li pellets and neutral particle analysis are presented. When a pellet is injected into the plasma, a toroidally extended ablation cloud is formed that travels with the pellet. A small fraction of the fusion alphas incident on the cloud are converted to helium neutrals as a result of electron capture processes. The escaping energetic helium neutrals are analyzed and detected by the neutral particle analyzer. Radially resolved energy spectra of trapped confined alphas in $0.5-2 \mathrm{MeV}$ range and radial alpha density profiles are presented in this paper. The experimental data are compared with modeling results obtained with the TRANSP Monte-Carlo Code and with a specially developed Fokker-Planck Post Processor (FPP) that uses the alpha source distribution produced by TRANSP. Comparison of the experimental data with TRANSP and FPP show that the alphas in the plasma core of sawtooth free discharges in TFTR are well confined and slow down classically. The energy and radial profiles distributions outside the plasma core show the influence of stochastic ripple losses on alphas. Measurements for sawtoothing plasmas show a significant outward radial transport of trapped alphas.
\end{abstract}

DISTRIBUTION OF THIS DOCUMENT IS UNLIMITED 


\section{Introduction}

The effective operation of a DT fusion reactor requires that the alpha particles generated in DT fusion reactions be well confined to allow deposition of most of the alpha energy in the plasma before they are lost. In other words, the time scale for radial diffusion of the alphas must be longer than their slowing down time in the plasma core. Therefore, radially resolved measurements of density and energy spectra of slowing down alphas confined in the plasma are very important.

Several diagnostic proposals have been made to measure confined alphas in large tokamaks. Some of them recently began to be used in the tokamak experiments; namely, charge exchange spectroscopy [1], microwave scattering[2], and energetic neutral particle analysis with the use of Li pellets[3,4]. The last method, which we call PCX (Pellet Charge Exchange), was developed in a collaboration between General Atomics, the A.F.Ioffe Physical-Technical Institute and the Princeton Plasma Physics Laboratory and is now operated routinely on TFTR during D-T experiments. The first results of the PCX diagnostic obtained during DT experiments on TFTR in 1994 were reported previously[5]. In this paper we present recent PCX results which extend the studies of alpha energy spectra and radial density distributions and examine the influence of magnetic field ripple and sawtooth oscillations on the alpha behavior.

\section{Experimental Layout.}

The PCX diagnostic on TFTR uses impurity pellets injected along a midplane major radius. The pellet injector, which was built by MIT, was operated with cylindrical Li pellets of $1.7 \mathrm{~mm}$ diameter by $3 \mathrm{~mm}$ length containing $7.3 \times 10^{19}$ atoms injected at velocities of $500-700 \mathrm{~m} / \mathrm{s}$. The Neutral Particle Analyzer (NPA) views the pellet from behind with a sight line at a toroidal angle of $2.75^{\circ}$ to the pellet trajectory. Consequently, only near perpendicular alphas with velocities close to $V \| / V=0.048$ are detected in these experiments. Upon entering the plasma, the pellet forms a toroidally elongated ablation cloud which travels with the pellet into the plasma. A small fraction of the alphas incident on the cloud is neutralized either by sequential single electron capture $\left(\mathrm{He}^{2+}\right.$ 
$+\mathrm{Li}^{+} \Rightarrow \mathrm{He}^{+}+\mathrm{Li}^{2+}$ followed by $\left.\mathrm{He}^{+}+\mathrm{Li}^{+}=>\mathrm{He}^{\mathrm{O}}+\mathrm{Li}^{2+}\right)$ or by double electron capture ( $\left.\mathrm{He}^{2+}+\mathrm{Li}^{+}=\mathrm{He}^{\mathrm{O}}+\mathrm{Li}^{3+}\right)$. The escaping helium neutrals are mass and energy analyzed using a high energy $\left(0.5\right.$ to $4 \mathrm{MeV}$ for ${ }^{4} \mathrm{He}^{+2}$ ) neutral particle analyzer (NPA GEMMA-2) that was designed, manufactured and calibrated by the Ioffe Institute[6] with the use of a cyclotron accelerator. The NPA is an E II B type and has eight energy channels with scintillator/phototube detectors that are operated in the analog mode. Although these detectors are relatively insensitive to neutrons, for DT operations on TFTR it was necessary to install lead and polyethylene shielding around the NPA which attenuated the DT neutrons by a factor of 150 .

By measuring of the energy distribution, $\mathrm{dn}_{\mathrm{O}} / \mathrm{dE}$, of helium neutrals escaping from the plasma the energy distribution of the incident alpha particles, $\mathrm{dn}_{\alpha} / \mathrm{dE}$, can be determined using:

$$
\mathrm{dn} \alpha_{\alpha} / \mathrm{dE}=\mathrm{dn} \mathrm{o}_{\mathrm{O}} / \mathrm{dE}\left[\mathrm{F}_{0}(\mathrm{E})\right]^{-1}
$$

where $\mathrm{F}_{\mathrm{o}}(\mathrm{E})$ is the equilibrium fraction of incident alphas neutralized in the cloud as a function of alpha energy. The value of $F_{o}(E)$ is obtained from modeling calculations[5].

The NPA views the radially injected pellet from behind and the radial position of the pellet as a function of time is measured using a linear photodiode array situated on the top of the vacuum vessel. By combining this measurement with the time dependence of the observed helium neutral signal, radially resolved alpha energy spectra and alpha density radial profiles can be derived with a radial resolution of $\sim 5 \mathrm{~cm}$. Pellets were injected 0.2 to $0.5 \mathrm{sec}$ after the neutral beam heating was turned off. This timing delay leads to deeper penetration of the pellet as a result of decay of the electron temperature as well as to enhanced signal-to-noise ratio because the neutron background decays significantly faster than the confined alpha population.

\section{Modeling of the PCX Measurements}

During the analysis of first PCX experimental results, we found that three factors can have a significant influence on interpretation of the measurements. These are: 1) the classical slowing 
down process, 2) toroidal magnetic field ripple, and 3) sawtooth oscillations which usually occur after termination of neutral beam injection. In analyzing the PCX data, we have attempted to take these effects into account by using two numerical modeling codes. First of all, we used the TRANSP[7] Monte-Carlo Code which follows the orbits of alphas as they slow down and pitch angle scatter by Coulomb collisions with the background plasma. TRANSP assumes that alphas are well confined during the slowing down and takes into account the spatial and temporal distributions of plasma parameters in each particular shot. Also, TRANSP was recently modified to include the stochastic ripple diffusion of alphas[8]. To model ripple effects for analysis of the PCX measurements, it is necessary to constrain integration of the alpha pitch angle to a narrow range around the PCX observation angle, $v_{\|} / V=0.048$, because of the dependence of alpha confinement time in the stochastic ripple diffusion domain on pitch angle Since the Monte-Carlo methods used in TRANSP give noisy results, we developed a post processor code(FPP) based on a numerical solution of the drift-averaged Fokker-Planck equation which uses the pitch angle integrated alpha source distribution provided by TRANSP. This code includes ripple effects, but the collisional integral used in the Fokker-Planck equation does not include pitch angle scattering or velocity diffusion. The alpha confinement time, $\tau_{\delta}$, is determined by stochastic ripple diffusion using the results of [9], where the following approximate formula for $\tau_{\delta}$ provides a smooth transition to the stochastic regime:

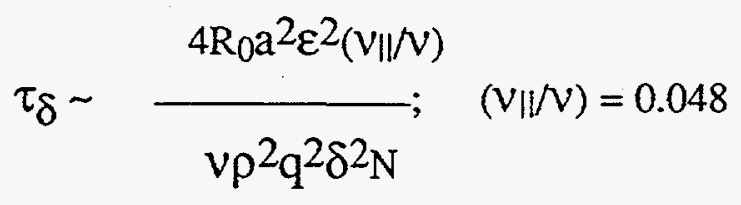

Here $V$ is the alpha velocity, $\rho$ is the Larmor radius, $\delta$ is the magnetic field ripple amplitude, and $\mathrm{N}$ is the number of toroidal coils. The Fokker-Planck equation was solved numerically by the method of integration over the particle characteristics[10]. The FPP calculations are in good agreement with TRANSP Monte-Carlo modeling. 


\section{PCX Experimental Data and Modeling Results.}

As pointed out earlier, the alpha particle distributions measured by the PCX diagnostic can be influenced by the effects of classical slowing down, magnetic field ripple and sawtooth activity. The effect of stochastic ripple diffusion was investigated by obtaining PCX measurements under sawtooth free conditions, as is discussed next.

\section{A) Studies of Alphas in Sawtooth Free Conditions.}

It is well known that stochastic toroidal field ripple diffusion is a mechanism that causes fast trapped particle loss in tokamaks[11,12]. Of course, this effect can be very important for trapped fusion alphas. The PCX diagnostic measures radially resolved energy spectra as well as radial profiles of the trapped alpha density and therefore is well suited for studying alpha stochastic ripple diffusion. To separate the influence of stochastic ripple diffusion and sawtooth oscillations on the alpha distribution, PCX data were obtained in sawtooth free DT plasmas where only the ripple effect and slowing down play a role. The discharge conditions were: $I_{p}=2 \mathrm{MA}, R=2.52$ $\mathrm{m}$, and $\mathrm{BT}=5 \mathrm{~T}$ with $20 \mathrm{MW}$ of DT neutral beam power injection for $1.1 \mathrm{~s}$. For high power neutral beam heated discharges in TFTR, the sawtooth instabilities usually begin $0.2-0.3 \mathrm{~s}$ after neutral beam termination. As shown in Fig. 1a, PCX data before a sawtooth crash was obtained on discharge \#84550 by injecting two Li pellets $0.3 \mathrm{~s}$ after beam termination with a $10 \mathrm{~ms}$ interval between them (stacked pellets). Under these conditions the first pellet rapidly lowered the electron temperature by a factor of two, thereby improving the penetration conditions for second pellet which reached the plasma core. PCX alpha density radial profiles in sawtooth free conditions for alpha energies of $0.64 \mathrm{MeV}$ and $1.21 \mathrm{MeV}$ are presented in Fig 2 ( $a$ and $b$ ) together with TRANSP results for modeling both with and without ripple effects. It can be seen that the experimental alpha density profiles agree well with the profiles predicted by TRANSP with the ripple model whereas the TRANSP profiles without ripple are much broader. The error bars in Fig. 2 only reflect the statistical errors due to the counting statistics. As discussed in [13], uncertainties in the pellet 
cloud density and ionization state can lead to additional uncertainties in the fraction of alphas neutralized in the cloud. Hence there is an additional uncertainty in the measured alpha density profiles. As also shown in [13], this uncertainty does not affect measurements of the alpha energy spectrum. Radially resolved alpha energy spectra for the same shot near the plasma core $(r=0.05$ $\mathrm{m})$ and farther outboard $(\mathrm{r}=0.17 \mathrm{~m})$ are presented in Fig.3( $\mathrm{a}$ and $\mathrm{b})$. The discrete points correspond to the various energy channels of the NPA. The Fokker-Planck Post-processor (FPP) calculations with and without ripple are shown as well. In addition we show in Fig 3-a the results of TRANSP modeling for the plasma core under classical slowing down conditions (i.e without ripple or sawteeth). It is seen that in the plasma core the PCX data are in good agreement with both TRANSP and FPP. This agreement implies that alphas in the core of sawtooth free plasmas are well confined and slow down classically with no influence from ripple effects. The coincidence of TRANSP and FPP results in this case also provides validation of the FPP code for the plasma center. Outside the plasma core (Fig.3-b) we compare the experimental data with FPP calculations with and without ripple. Note that the normalization of the PCX and modeling data was made only once for the plasma core case as it is shown in Fig.3-a. Using the same normalization outside the plasma core (Fig.3-b), we see good agreement of PCX data with FPP with ripple and significant deviations from FPP without ripple. These deviations indicate that slowing down alphas are being influenced by ripple stochastic diffusion and do not develop a complete slowing down population because of the reduced confinement time.

\section{B) Studies of Alphas in the Presence of Sawtooth Activity}

The influence of sawtooth effects on fast particles in tokamaks has been discussed in theoretical and experimental papers based on the measurements of injected neutral beam ions, RF driven minority ions and fusion products in DD plasmas[14-16]. The analysis showed that passing fast particles can be influenced by sawtooth mixing but it was noted that trapped particles should not be sensitive to this phenomena. Until now there has been no direct experimental measurements of the influence of sawtooth mixing on DT trapped alphas. This issue is important 
because sawtooth activity can cause rapid expulsion of the alphas from the plasma core which, in turn, can not only quench ignition in a tokamak reactor but also lead to damage of the vessel components by synergistically feeding the alphas into the stochastic ripple and prompt loss region. Below we describe the first experiments which study the influence of sawtooth activity on the behavior of trapped fast DT alphas in TFTR.

To obtain PCX data following the first sawtooth crash, two stacked pellets were injected $0.4 \mathrm{~s}$ after termination of neutral beam heating in discharge $\# 84549$ as shown in Fig. $1 \mathrm{~b}$. This shot had similar parameters to discharge \#84550 described above for the sawtooth free condition. The PCX alpha measurements in the energy range $0.64-1.21 \mathrm{MeV}$ are plotted as a function of the plasma major radius in Fig.4 (a,b,c,d) for both discharges \#84550 and \#84549. The data for \#84550 (before the first sawtooth) were derived from the second of two stacked pellets while the data for \#84549 (after the first sawtooth) correspond to the first pellet. Also plotted are the FPP results for alpha density profiles in discharge $\# 84550$ normalized to PCX data which show that before the sawtooth crash, the profiles agree well with FPP calculations including stochastic ripple diffusion. It is also clear that after the sawtooth crash, the PCX data indicate that a significant broadening of the trapped alpha density profile occurs and that this broadening increases with decreasing energy.

It is interesting to compare the observed alpha density radial profiles with the radial dependence of stochastic ripple diffusion confinement time. Contour maps of alpha confinement time determined by the stochastic ripple diffusion versus the plasma major radius $\mathrm{R}$ and vertical axis $Z$ for two alpha energies (3.52 and $1.21 \mathrm{MeV}$ ) are shown in Fig. 5. The values of confinement time, $\tau_{\delta}$, are calculated from equation (2) for discharges $\# 84550$ at $\mathrm{E}_{\alpha}=3.52 \mathrm{MeV}$ and $\# 84549$ at $\mathrm{E}_{\alpha}=1.21 \mathrm{MeV}$. Such maps present a smooth transition zone between the stochastic free domain in the plasma core and stochastic domain outside for the selected alpha particle energy at the PCX pitch angle of $v_{\|} / v=0.048$. Across this transition zone, the confinement time, $\tau_{\delta}$, decreases from $170 \mathrm{~ms}$ (inner boundary) to $20 \mathrm{~ms}$ (outer boundary). From these plots, the midplane radial extent of the transition zones is approximately $R=2.90-3.10 \mathrm{~m}$ for the alpha birth energy, $E_{\alpha}=3.52 \mathrm{MeV}$, and $\mathrm{R}=3.08-3.20 \mathrm{~m}$ for an alpha energy of $\mathrm{E}_{\alpha}=$ 
1.21 MeV. In Fig. 6, measured alpha density radial profiles before and after the sawtooth crash are presented for the alpha energy $E_{\alpha}=1.21 \mathrm{MeV}$ together with the radial stochastic diffusion transition zones for alpha energies of $3.5 \mathrm{MeV}$ and $1.21 \mathrm{MeV}$. It is clearly seen that the experimental alpha density profile for the sawtooth free case becomes depleted at the radial location of transition zone for an alpha energy of $3.5 \mathrm{MeV}$. From this result we infer that under sawtooth free conditions, no significant radial transport of the alphas occurs during their slowing down from 3.5 MeV to $1.21 \mathrm{MeV}$. Without radial transport these particles can not exist on the right side of the transition zone for $3.5 \mathrm{MeV}$ alphas. After the sawtooth crash the $1.21 \mathrm{MeV}$ alphas appear in the region outboard of the $3.5 \mathrm{MeV}$ transition zone, but becomes depleted at the transition zone for $1.21 \mathrm{MeV}$ alphas. Again, the experimental density radial profile is consistent with the predicted stochastic ripple transition. From this behavior, we infer that the sawtooth crash transports alpha particles out to the energy dependent radial position of the stochastic diffusion transition zone where they are rapidly lost due to ripple diffusion.

The measured alpha energy spectra in the plasma core before the sawtooth crash ( $\# 84550$ ) and at $\mathrm{R}=2.9 \mathrm{~m}$ after the sawtooth crash (\#84549) are presented in Fig. 7. The fact that the energy spectrum steepens after the crash provides additional confirmation that following radial transport by the sawtooth crash, the high energy alpha particles are lost predominantly as a result of ripple diffusion.

\section{Conclusions}

With the present configuration on TFTR, the PCX diagnostic detects deeply trapped confined alphas which are most critical to first orbit and ripple diffusion losses in tokamaks. To date, PCX diagnostics has yielded data on radially resolved confined alpha particle energy spectra and radial density profiles in the energy range $0.5-2.5 \mathrm{MeV}$. The measurements are reproducible, have minimal neutron background interference and are limited only by the signal statistics determined by the neutralization efficiency of pellet ablation cloud and the analyzer sensitivity. The existing uncertainties in pellet cloud ionization states lead to uncertainties in PCX absolute signal 
but not in the shape of the alpha energy spectrum. Thus the measured spectra are presented in arbitrary units normalized to the corresponding modeling data.' The PCX studies of energetic confined alphas in TFTR DT plasmas presented in this paper allow the following conclusions to be drawn:

1) In the TFTR plasma core under sawtooth free conditions, trapped alpha particles are well confined and slow down classically.

2) In more radially outboard plasma regions, the trapped alphas begin to be affected by stochastic ripple diffusion.

3) Post neutral beam injection sawtooth oscillations in TFTR effectively transport fast trapped alphas radially outwards into the stochastic ripple loss region. This transport can lead to enhanced first orbit and ripple losses of trapped fast alphas.

4) The radial transport of trapped alphas by sawtooth instabilities evidenced by the experimental results presented in this paper can be very important for ITER where the attendant alpha energy loss may cause first wall damage. Further experimental investigation of this transport process and improvements in the modeling of sawtooth alpha mixing are in progress.

\section{Acknowledgements}

This work was supported by US DoE Contract DE-AC02-76-CHO-3073 and US DoE Grant DE-FG03-92ER54150. 


\section{References}

[1] G. McKee, R. J. Fonck, B. C. Stratton, et al.,"Confined Alpha Distribution Measurements in a Deuterium-Tritium Tokamak Plasma," submitted to Phys. Rev. Lett. (1995).

[2] P. P. Woskov, J. S. Machuzak, R. C. Myer, et al., Rev.Sci. Instrum. 59, 1565 (1988)

[3] R. K. Fisher, J. S. Leffler, A. W. Howald, et al., Fusion Technol. 13, 536 (1988) and Rèv. Sci. Instrum. 63,4499 (1992)

[4] R. K. Fisher, J. M. McChesney, A. W. Howald, et al., Rev. Sci. Instrum. 63, 4499 (1992)

[5] R. K. Fisher, J. M. McChesney, P. B. Parks, et al., "Measurements of Fast Confined Alphas on TFTR," submitted to Phys. Rev. Lett. (1995)

[6] A. B. Izvozchikov, A. V. Khudoleev, M. P. Petrov, et al., JET Joint Undertaking, Abingdon, Oxfordshire, England, Report JET-R(91) 12, (1991)

[7] R. V. Budny, Nucl. Fusion 34, 1247 (1994)

[8] M. H. Redi, R. V. Budny, D. S. Darrow, et al.,"Modeling of TF Ripple Loss of Alpha Particles in TFTR DT Experiment," to be submitted to Nucl. Fusion (1995)

[9] P. N. Yushmanov, Nucl. Fusion 23, 1599 (1983)

[10] N. N. Gorelenkov and S. V. Putvinskij, Sov.J. Plasma Phys. 15, 80 (1989) 
[11] R. J. Goldston, R. B. White and A. H. Boozer, Phys. Rev. Lett. 47, 647 (1981)

[12] R. L. Boivin, S. J. Zweben and R. B. White, Nucl. Fusion 33, 449 (1993)

[13] J. M. McChesney, P. B. Parks and R. K. Fisher, "Neutralization Fractions for Alpha Particles Interacting with Lithium Pellet Ablation Clouds," to be submitted to Nucl. Fusion, GA-A21958 (1995)

[14] H. H. Duong and W. W. Heidbrink, Nucl. Fusion 33, 211 (1993)

[15] F. B. Marcus, J. M. Adams, D. S. Bond, et al., Nucl. Fusion 34, 687 (1994)

[16] Ya. I. Kolesnichenko, V. V. Lutsenko and Yu. V. Yakovenko, et al., Nucl. Fusion 34, 1619 (1994) 


\section{Figure Captions}

Fig. 1 The time scenarios for $\mathrm{Li}$ pellet injection following termination of neutral beam injection in TFTR: a) before the first sawtooth crash (\#84550) and b) after the first sawtooth_crash ( \#84549).

Fig.2 PCX alpha density radial profiles for two alpha energies under the sawtooth free conditions ( $\mathrm{t} \# 84550$ ) and preliminary profiles predicted by the TRANSP Code with and without modeling of toroidal field ripple.

Fig.3 PCX alpha energy spectra for two radial positions together in sawtooth free shot 84550 with corresponding spectra predicted by TRANSP and FPP Code.

Fig. 4 PCX alpha density radial profiles for four alpha energies before (\$84550) and after (\#84549) a sawtooth crash together with the profile for discharge \#84550 predicted by the FPP code.

Fig.5 Contour maps of alpha particle confinement times determined by the stochastic ripple diffusion in TFTR for two alpha particle energies.

Fig.6 PCX alpha density radial profiles for an alpha energy of $1.21 \mathrm{MeV}$ measured before (\#84550) and after (\#84549) a sawtooth crash together with the profile predicted by the FPP code for discharge \#84550. The stochastic diffusion transition zones for alpha energies of $3.5 \mathrm{MeV}$ and $1.21 \mathrm{MeV}$ are shown by the hatched regions.

Fig.7 PCX alpha energy spectra before (\#84550) and after (\#84549) the sawtooth crash. 


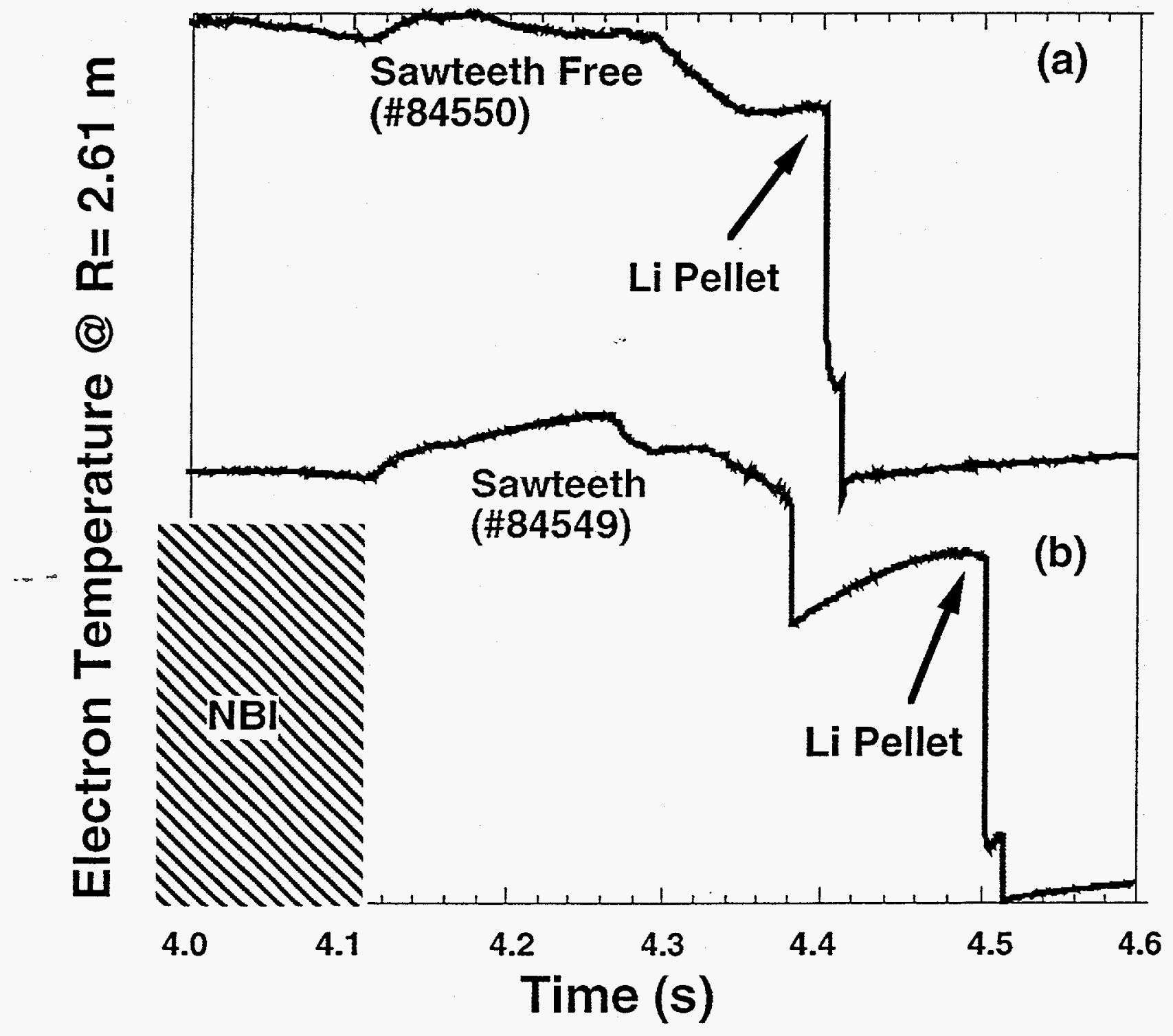

Fig. 1 
$\stackrel{\frac{\pi}{6}}{\frac{\pi}{0}}$

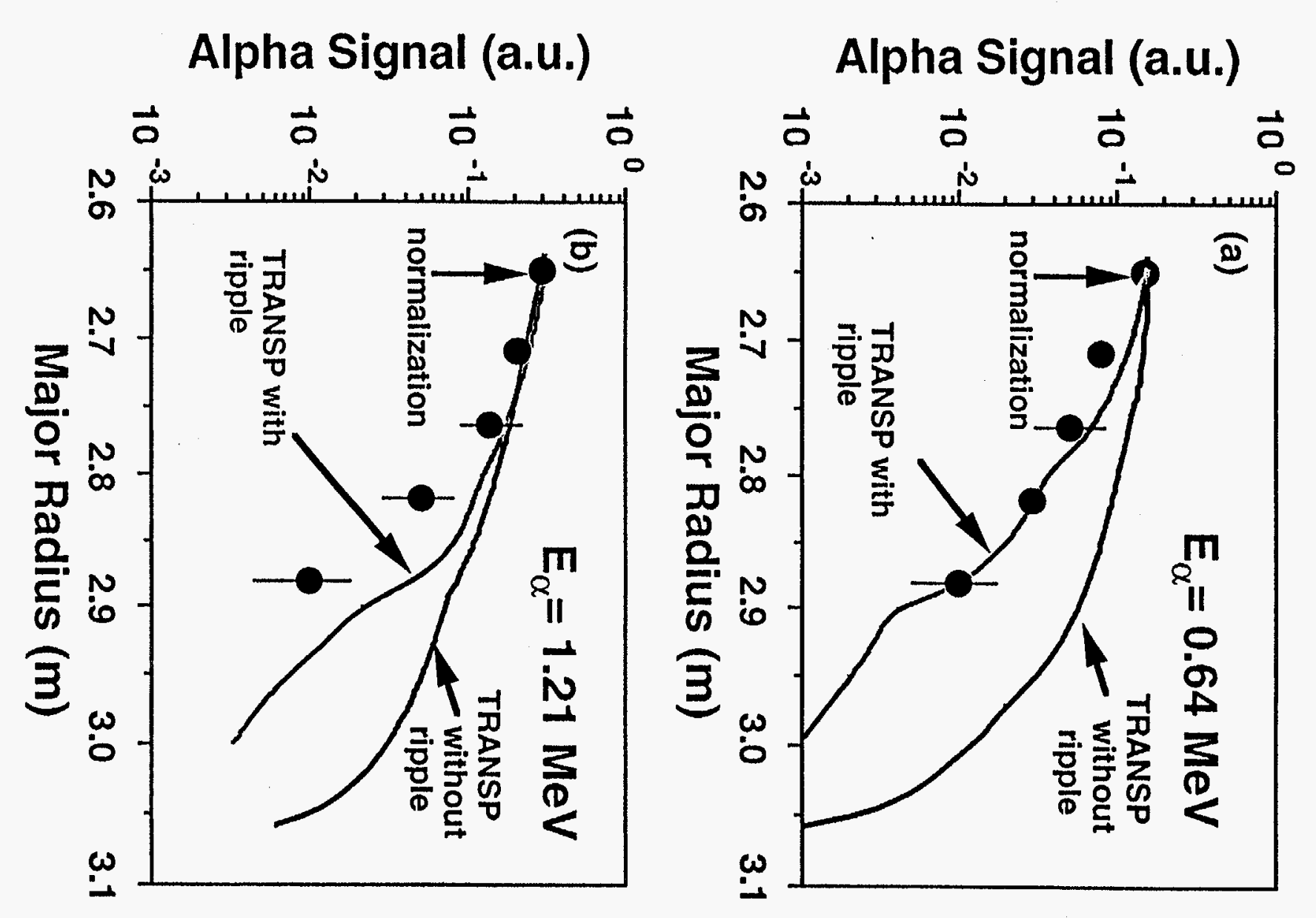



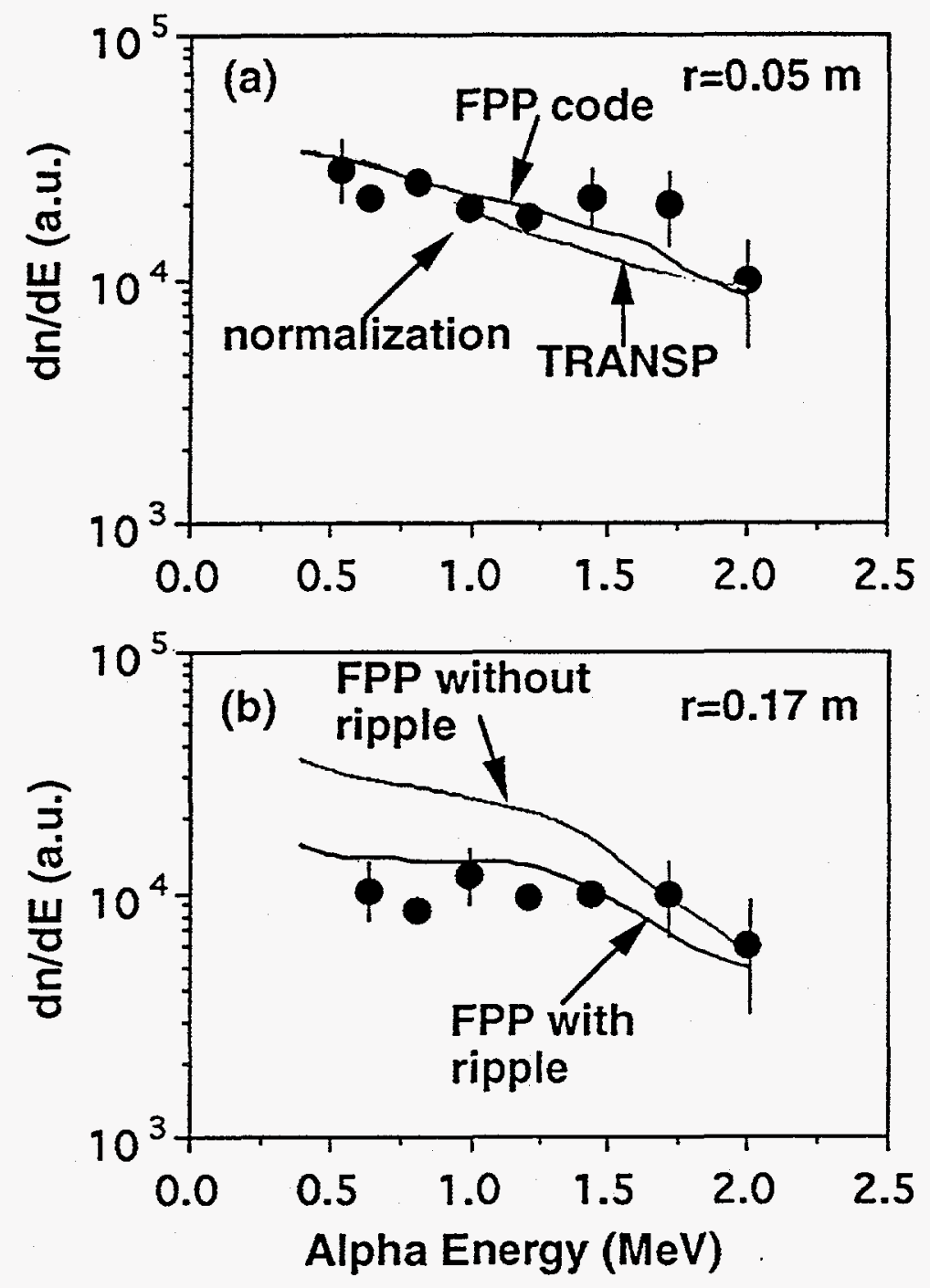

Fig. 3 

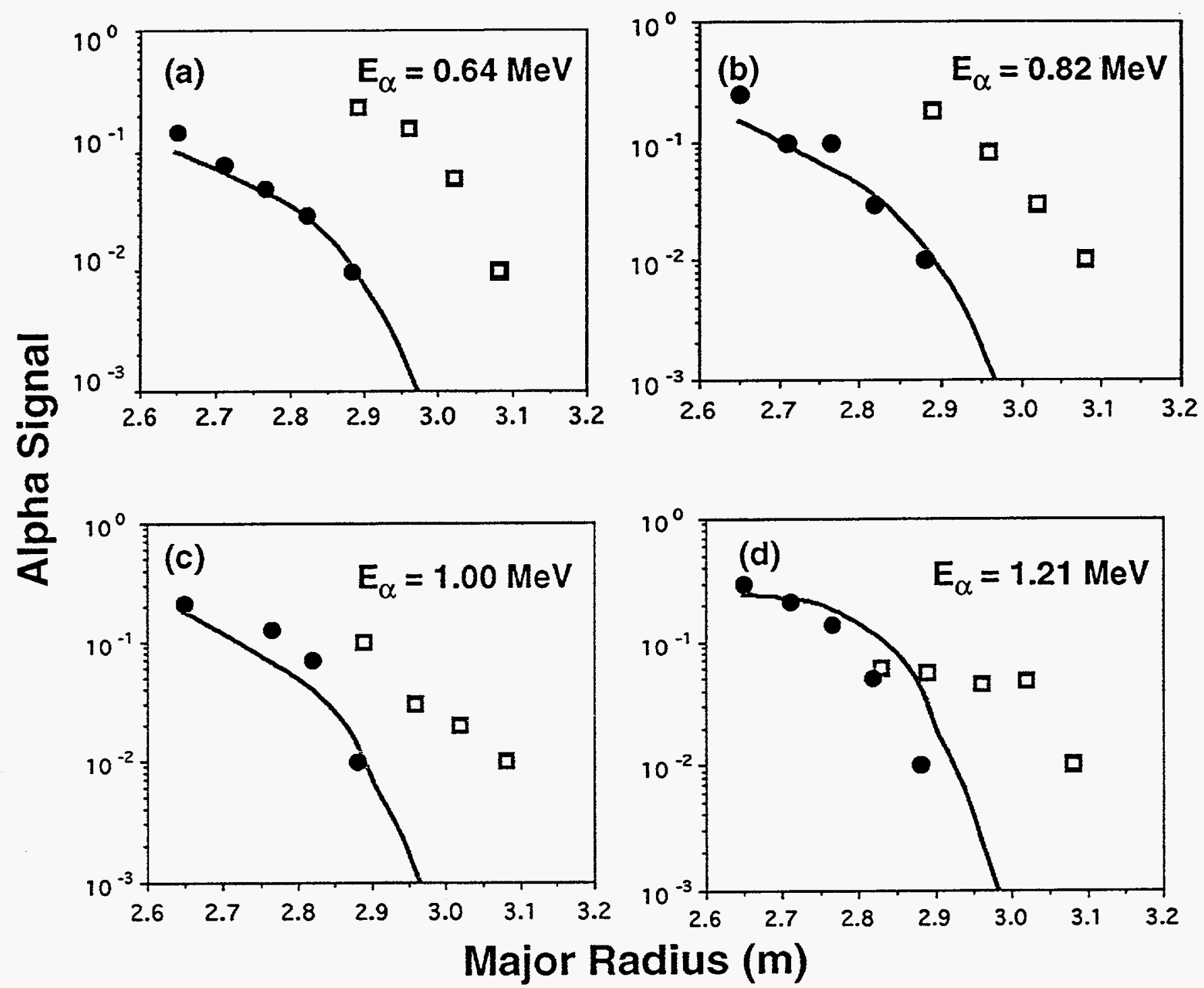

- Before Sawtooth Crash (\#84550)

D After Sawtooth Crash (\#84549)

- FPP Code

Fig. 4 

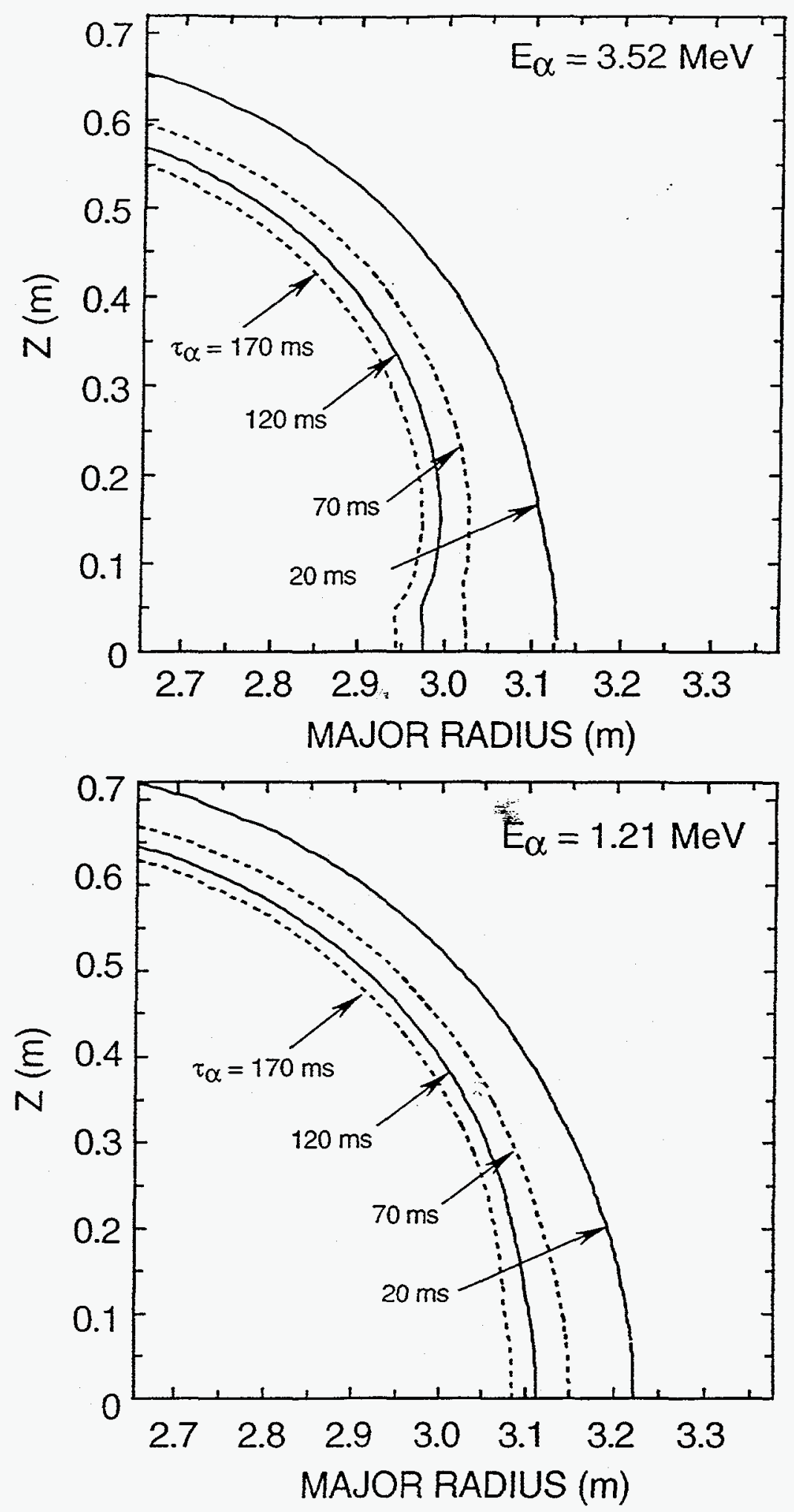

Fig. 5 


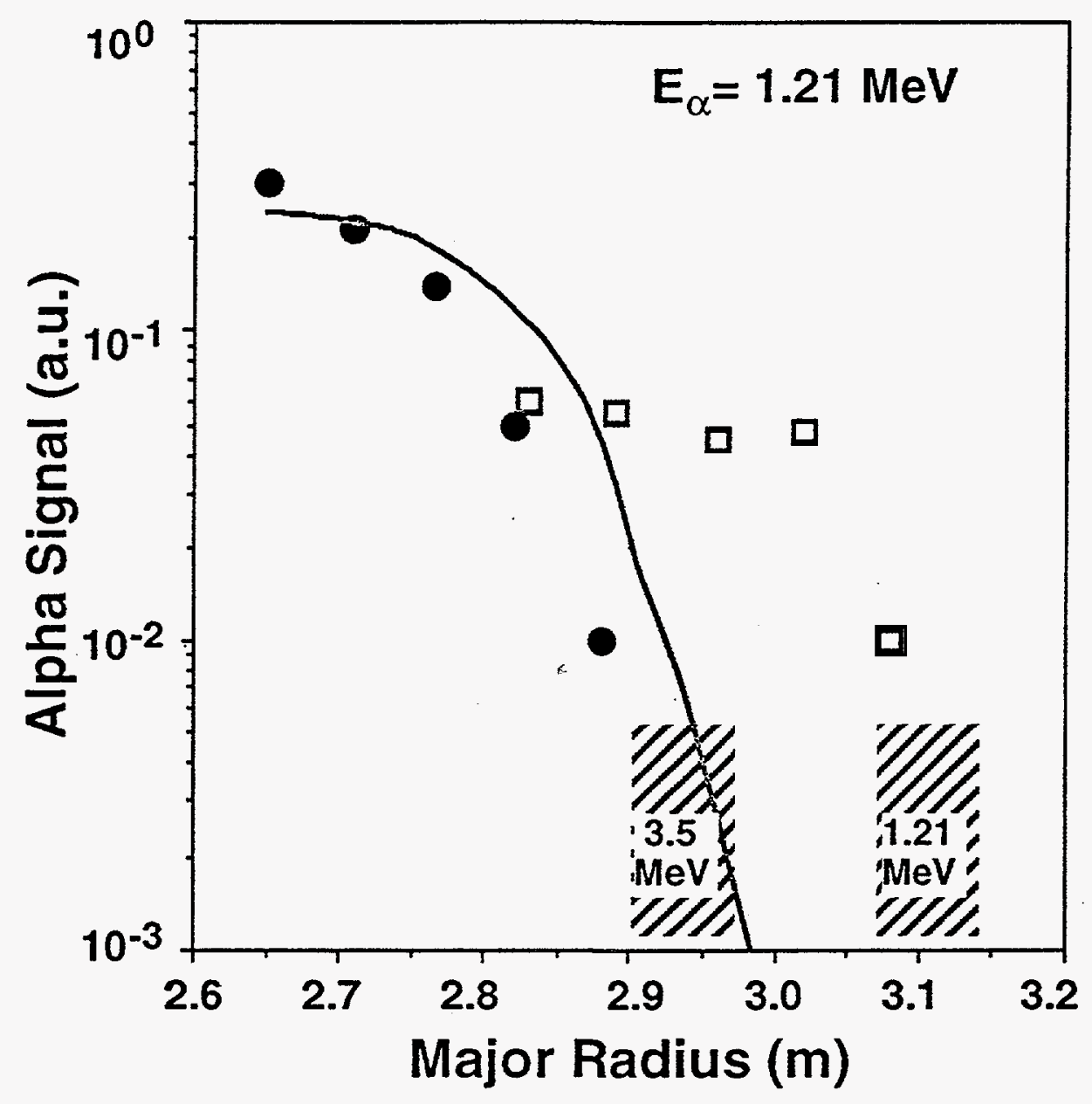

- Before Sawteeth (\#84550)

$\square$ After Sawteeth (\#84549)

- FPP Code

W Stochastic Diffusion Transition Zone

left boundary: $\tau_{\delta}=170 \mathrm{~ms}$; right boundary: $\tau_{\delta}=70 \mathrm{~ms}$

Fig. 6 


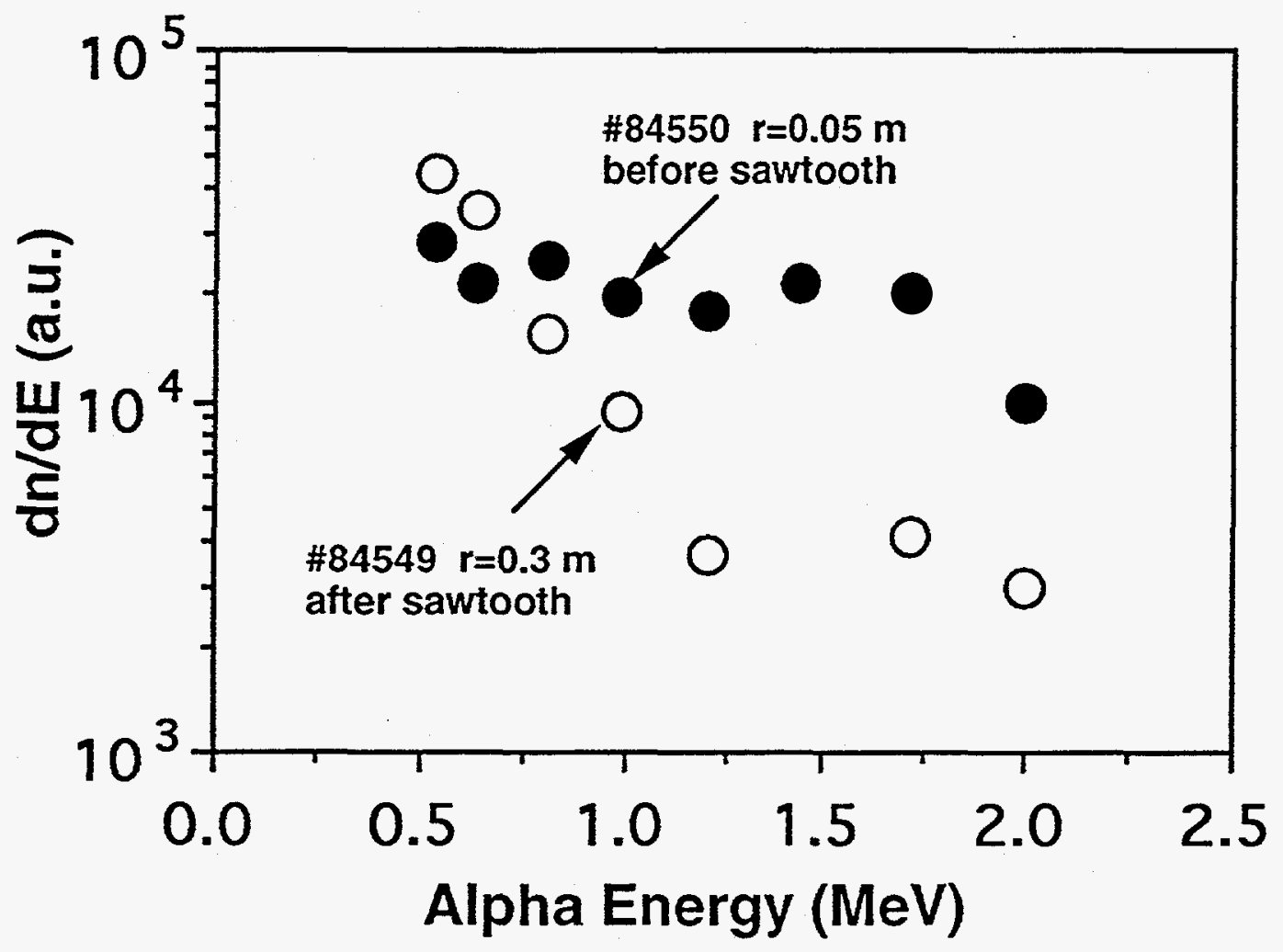

Fig. 7 
Dr. F. Paoloni, Univ. of Wollongong, AUSTRALIA

Prof. R.C. Cross, Univ. of Sydney, AUSTRALIA

Plasma Research Lab., Australian Nat. Univ., AUSTRALIA

Prof. I.R. Jones, Flinders Univ, AUSTRALIA

Prof. F. Cap, Inst for Theoretical Physics, AUSTRIA

Prof. M. Heindler, Instiut für Theoretische Physik, AUSTRIA

Prof. M. Goossens, Astronomisch Instituut, BELGIUM

Ecole Royale Militaire, Lab. de Phy. Plasmas, BELGIUM

Commission-European, DG. XII-Fusion Prog., BELGIUM

Prof. R. Bouciqué, Rijksuniversiteit Gent, BELGIUM

Dr. P.H. Sakanaka, Instituto Fisica, BRAZIL

Prof. Dr. I.C. Nascimento, Instituto Fisica, Sao Paulo, BRAZIL Instituto Nacional De Pesquisas Espaciais-INPE, BRAZIL Documents Office, Atomic Energy of Canada Ltd., CANADA Ms. M. Morin, CCFMTokamak de Varennes, CANADA Dr. M.P. Bachynskj, MPB Technologies, Inc., CANADA Dr. H.M. Skarsgard, Univ. of Saskatchewan, CANADA Prof. J. Teichmann, Univ. of Montreal, CANADA Prof. S.R. Sreenivasan, Univ. of Calgary, CANADA Prof. R. Marchand, INRS-Energie et Materiaux, CANADA Dr. R. Bolton, Centre canadien de fusion magnétique, CANADA Dr. C.R. James, Univ. of Alberta, CANADA

Dr. P. Lukác, Komenského Universzita, CZECHO-SLOVAKIA

The Librarian, Culham Laboratory. ENGLAND

Library, R61, Rutherford Appleton Laboratory, ENGLAND

Mrs. S.A. Hutchinson, JET Library, ENGLAND

Dr. S.C. Sharma, Univ. of South Pacific, FIJI ISLANDS

P. Mähönen, Univ. of Helsinki, FINLAND

Prof. M.N. Bussac, Ecole Polytechnique, FRANCE

C. Mouttet, Lab. de Physique des Milieux lonisés, FRANCE

J. Radet, CEN/CADARACHE - Bat 506, FRANCE

Prof. E. Economou, Univ. of Crete, GREECE

Ms. C. Rinni, Univ. of loannina, GREECE

Preprint Library, Hungarian Academy of Sa., HUNGARY

Dr. B. DasGupta, Saha Inst. of Nuclear Physics, INDIA

Dr. P. Kaw, Inst. for Plasma Research, INDIA

Dr. P. Rosenau, Israel Inst. of Technology, ISRAEL

Librarian, Intemational Center for Theo Physics, ITALY

Miss C. De Palo, Associazione EURATOM-ENEA, ITALY

Dr. G. Grosso, Istituto di Fisica del Plasma, ITALY

Prof. G. Rostangni, Istituto Gas lonizzati Del Cnr, ITALY
Dr. H. Yamato, Toshiba Res \& Devel Center, JAPAN

Prof. I. Kawakami, Hiroshima Univ., JAPAN

Prof. K. Nishikawa, Hiroshima Univ., JAPAN

Librarian, Naka Fusion Research Establishment, JAERI, JAPAN

Director, Japan Atomic Energy Research Inst., JAPAN

Prof. S. Itoh, Kyushu Univ., JAPAN

Research Info. Ctr., National Instit. for Fusion Science, JAPAN

Prof. S. Tanaka, Kyoto Univ., JAPAN

Library, Kyoto Univ., JAPAN

Prot. N. Inoue, Univ. of Tokyo, JAPAN

Secretary, Plasma Section, Electrotechnical Lab., JAPAN

Dr. O. Mitarai, Kumamoto Inst. of Technology, JAPAN

Di. G.S. Lee, Korea Basic Sci. Ctr., KOREA

J. Hyeon-Sook, Korea Atomic Energy Research Inst, KOREA

D.I. Choi, The Korea Adv. Inst. of Sci. \& Tech., KOREA

Leandro Melendez Lugo, Inst. Nac1. de Inves. Nud, MEXICO

Prof. B.S. Liley, Univ. of Waikato, NEW ZEALAND

Inst of Physics, Chinese Acad Soi PEOPLE'S REP. OF CHINA

Library, Inst. of Plasma Physics, PEOPLE'S REP. OF CHINA

Tśsinghua Univ. Library, PEOPLE'S REPUBLIC OF CHINA

Z. Li, S.W. Inst Physios, PEOPLE'S REPUBLIC OF CHINA

Prof. J.A.C. Cabral, Instituto Superior Tecnico, PORTUGAL

Prof. M.A. Hellberg, Univ. of Natal, S. AFRICA

Prof. D.E. Kim, Pohang Inst. of Sci. \& Tech., SO. KOREA

Prof. C.I.E.M.A.T, Fusion Division Library, SPAIN

Dr. L. Stenflo, Univ. of UMEA, SWEDEN

Library, Royal Inst. of Technology, SWEDEN

Prof. H. Wilhelmson, Chalmers Univ. of Tech., SWEDEN

Centre Phys. Des Plasmas, Ecole Polytech, SWITZERLAND

Bibliotheek, Inst. Voor Plasma-Fysica, THE NETHERLANDS

Asst. Prof. Dr. S. Cakir, Middle East Tech. Univ., TURKEY

Dr. V.A. Glukhikh,Sci. Res. Inst. Electrophys.l Apparatus, USSR

Dr. D.D. Ryutov, Siberian Branch of Academy of Sci., USSR

Dr. G.A. Eliseev, I.V. Kurchatov Inst., USSR

Librarian, The Ukr.SSR Academy of Sciences, USSR

Or. L.M. Kovrizhnykh, Inst. of General Physics, USSA

Kernforschungsanlage $\mathrm{GmbH}$, Zentralbibliothek, W. GERMANY

Bibliothek, Inst. Für Plasmaforschung, W. GERMANY

Prof. K. Schindier, Ruhr-Universitát Bochum, W. GERMANY

Dr. F. Wagner, (ASDEX), Max-Planck-Institut, W. GERMANY

Librarian, Max-Planck-Institut, W. GERMANY 